\title{
The Discrete Particle Swarm Optimization Algorithms for Multi-Objective Permutation Flowshop Scheduling Problem
}

\author{
Ikhlasul Amallynda \\ Department of Industrial Engineering, University Of Muhammadiyah Malang, Indonesia \\ Jl. Raya Tlogomas No. 246 Malang, Indonesia \\ Corresponding author: ikhlasulamallynda@umm.ac.id
}

\section{ARTICLE INFO}

\section{Article history}

Received March 28, 2019

Revised July 10, 2019

Accepted August 20, 2019

Available Online August 31, 2019

\section{Keywords}

Flow shop

Earliness

Tardiness

Metaheuristic

Particle swarm optimization

\begin{abstract}
In this paper, two types of discrete particle swarm optimization (DPSO) algorithms are presented to solve the Permutation Flow Shop Scheduling Problem (PFSP). We used criteria to minimize total earliness and total tardiness. The main contribution of this study was that a new position update method is developed based on the discrete domain because PFSP is represented as discrete job permutations. In addition, this article also comes with a simple case study to ensure that both the proposed algorithm can solve the problem well in a short computational time. Hybrid Discrete Particle Swarm Optimization (HDPSO) has a better performance than the Modified Particle Swarm Optimization (MPSO). The HDPSO produced the optimal solution. However, it has a slightly longer computation time. Besides, the population size and maximum iteration impact the quality of solutions produced by HDPSO and MPSO algorithms.
\end{abstract}

This is an open-access article under the CC-BY-SA license.

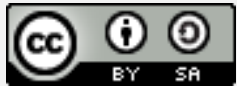

\section{Introduction}

The flow shop scheduling problem is one of the best-known production scheduling problems. It has been classified into an NP-complete problem. There are $\mathrm{n}$ jobs processed on $\mathrm{m}$ machines in the same order in the pure flow shop scheduling problem. The operation of every job must be processed on machine k. The Permutation Flow Shop Scheduling Problem (PFSP) is the same job sequence in all machines. Permutation schedules do not always cover the optimal schedule except for the case of two machines [1]. PFSP assumed a Static and deterministic environment. The processing time and due date are known. Moreover, all job is available for processing from the beginning. Preemptions are not permitted when the job begins to be processed on a machine. It cannot be interrupted. One of the most relevant flow shop applications was found in the chemical industry.

The primary purpose of the schedule is to find the optimal Job sequence. It is seen from some performance criteria, such as makespan, total flowtime, and mean lateness. Lateness measures the conformity of the schedule to a given due date. It has negative values whenever a job is completed early. Negative lateness represents earlier service 
than requested. The positive lateness represents that later service than requested job earliness may cause fixed capital and inventory holding costs. Furthermore, job tardiness may disrupt a customer's operations and incurring penalty fees. Therefore, both earliness and tardiness should be taken into account to determine the optimal machine scheduling policy. The sequence of jobs affects performance measures. Multiple objective functions are possible that the objective function is not optimal when other objective functions are optimized. There is a trade-off when there are two objective functions simultaneously optimized. Therefore, It is a multi-objective problem.

Some exact and heuristic algorithms have been proposed over the past decades. These have been used for solving the PFSP with the objectives of minimizing total earliness and total tardiness. Scheduling problems with multiple performances is a combinatorial problem that is classified into the NP-Hard problem. The best method to solve the NP-Hard problem is heuristic [2]. Some research has used a metaheuristic method to solved PSFP problems for single objective and multi-objective problems. Some that metaheuristics such as Tabu Search (TS) [3-7], Genetic Algorithm (GA) [8-14], Simulated Annealing (SA) [15-17], Particle Swarm Optimization (PSO) [18-22]. However, a few research considers minimizing the total earliness and total tardiness simultaneously in PFSP.

The PSO algorithm is an efficient algorithm for scheduling problems with various variations [23]. Originally, PSO has developed to solve continuous optimization problems. Scheduling is a discrete and combinatorial problem. This research modified PSO to solve the problem. This paper, This research proposes two PSO-based algorithms to find the optimal sequence in PFSP. This research used criteria minimizing total earliness and total tardiness simultaneously. The modifications are carried out by changing the speed update formula and by using a transition probability matrix. For the multi-objective function, we used the multi-objective function by Ronconi \& Birgin [24]. This paper's main contribution is that a new position update method is developed to be applied to all classes of combinatorial optimization problems in the literature. The rest of the paper is organized as follows. Section 2 presents the assumption, mathematical model, proposed algorithm, case study, and parameter setting. Section 3 describes results and discussion, and Section 4 is a conclusion and future work.

\section{Methods}

We modified some algorithms based on Hybrid Discrete Particle Swarm Optimization (HDPSO) algorithm by Clerc [25] and modified particle swarm optimization (MPSO) algorithm by Santosa, Siswanto \& Putawama [26] to solve the PFSP problem. We modified the HDPSO and MPSO formulation to reach the global optimal point accurately and efficiently.

\subsection{Assumptions}

Generally, the scheduling problem is divided into two types: flow shop and job shop scheduling. The flow shop scheduling attracts the researcher [27]. In the PFSP, a set of jobs $(\mathrm{N}=1,2,3, \ldots \mathrm{n})$ be processed through the set of machines $\mathrm{M}(\mathrm{M}=1,2,3, \ldots, \mathrm{m})$ in the same order. The processing times of the jobs at the machines are known, non-negative, and deterministic. Furthermore, some assumptions PFSP problems: 1) all jobs are independent and they ready to be processed at time $0 ; 2$ ) The machine is always available and ready to use (no damage); 3) Each machine only process one job at a time; 4) Each job only be processed on one machine at a time; 5) Any job that is being processed on one machine cannot be interrupted (no pre-emption); 6) Setup time is independent of the 
sequence and is included in the processing time; 7) Storage capacity between stages of operation (in process storage) is unlimited [2]. In scheduling, the possible sequence if there are $\mathrm{n}$ jobs is $\mathrm{n}$ !. in most literature, the search for solutions to this problem is Permutation Flow Shop Scheduling Problem (PFSP).

\subsection{Mathematical Model}

The mathematical model in this paper is the modification of Ronconi \& Birgin [24]. The model was developed by adding and changing constraints. The objective functions are minimizing total earliness and total tardiness. Two objective functions have some weight, and It to be minimized simultaneously.

$i \quad$ : operation index

$j \quad:$ job index

$k \quad$ : machine index

$p_{j k}$ : processing time of job $j$ at machine $k$

$d_{j}:$ due date of job $j$

$S_{i j}:$ starting time of job $j$ at operation $i$

$C_{i j}$ : completion time of job $j$ at operation $i$

$E_{j} \quad$ : earliness time of job $j$

$T_{j} \quad$ : tardiness time of job $j$

$x_{i j}$ : binary variable, 1 if job $j$ at operation $i$ and 0 if not

$\operatorname{Min} \sum_{j=1}^{n} E_{j}+T_{j}$

Constraint

$$
\begin{array}{ll}
T_{j} \geq C_{j m}-\sum_{i=1}^{n} x_{i j} d_{i} & j=1,2, \ldots, n \\
E_{j} \geq \sum_{i=1}^{n} x_{i j} d_{i}-C_{j m} & j=1,2, \ldots, n \\
C_{j m}=S_{j m}+\sum_{i=1}^{n} x_{i j} p_{i m} & j=1,2, \ldots, n \\
S_{j+1, k} \geq S_{j k}+\sum_{i=1}^{n} x_{i j} p_{i k} & j=1,2, \ldots, n-1, k=1,2, \ldots, m \\
S_{j, k+1} \geq S_{j k}+\sum_{i=1}^{n} x_{i j} p_{i k} & j=1,2, \ldots, n, k=1,2, \ldots, m-1 \\
S_{11} \geq 0 & \\
\sum_{i=1}^{n} x_{i j}=1 & j=1,2, \ldots, n \\
\sum_{j=1}^{n} x_{i j}=1 & j=1,2, \ldots, n
\end{array}
$$

Equation (1) is the multi-objective function to minimize total earliness and total tardiness simultaneously. Constraint (2) show the formula tardiness of each job. Constraint (3) explain the individual earliness of each job. Equation (4) describe the completion time of each job on the last machine. Constraints (5) - (7) show the rules for the starting time of each job on each machine. Constraint (5) describes the starting times of consecutive jobs on a machine. Constraint (6) indicates the starting times of a job on two consecutive machines. Constraint (7) shows that the first job's starting time on the first machine must be non-negative. Constraints (8) and (9) ensure that a job is allocated to a sequence position. These ensure each sequence positions only one job.

\subsection{Proposed Algorithm}

PSO is an algorithm based on swarm intelligence. It was proposed J. Kennedy and R. C. Eberhart [28]. PSO has three main components: particles, cognitive components, social components, and particle velocity. Moreover, each particle represents a solution. In Cognitive learning, pBest is the best position by a particle. Furthermore, gBest is the best position of the fundamental particle in the swarm. pBest is the best position of each particle among iterations. Moreover, gBest is the best of pBest. The disadvantage of PSO 
is the possibility of being trapped at local optimal. It is occurred to solve discrete optimization problems such as job scheduling. The modification by changing the updating mechanism can reduce the possibility of being trapped at local optimal. We developed two procedures. It is Hybrid Discrete Particle Swarm Optimization (HDPSO) and Modified Particle Swarm Optimization (MPSO).

\subsubsection{Hybrid Discrete Particle Swarm Optimization (HDPSO)}

Clerc [25] modified the Discrete Particle Swarm Optimization (DPSO) algorithm that Kennedy and Eberhart formulated. He modified the representation of the position of the particles, the shape of the velocity produced by the particles, and the effect of velocity on the position of the particles. The goal of these modifications is to be applied to problems with discrete models, especially types combinatorial. This research modified The structure of the DPSO algorithm by Clerc [25]:

1. Particles position

$$
x_{i}^{t}=\left[\begin{array}{llll}
x_{i 1}^{t} & x_{i 2}^{t} & . . & x_{i d}^{t}
\end{array}\right]
$$

Where, $x_{i}^{t}$ is the position of the $i^{t h}$-particle in the $t^{t h}$-iteration and the particle have as many as $d$ dimensions.

2. Transposition

Transposition is a way to exchange two values on a particular dimension based on the index sequence of the position of the particles.

3. Velocity

Velocity, as much as $\left\|v_{i}^{t}\right\|$ Transposition process between the two index positions.

Velocity is defined as follows:

$v_{i}^{t}=\left(\left(a_{k}, b_{k}\right)\right), a \in\{1,2, \ldots, d\}, b \in\{1,2, \ldots, d\}, k \uparrow_{1}^{\left\|v_{i}^{t}\right\|}$

$\left\|v_{i}^{t}\right\|$ is the number of lists of transpositions, $a$ and $b$ are the dimensional dimension indices that be exchanged for value. For example: $v_{1}=((1,3),(2,5))$ and $v_{2}=$ $((2,5),(1,3))$, then $v_{1} @ v_{2}$ said to be not the same; however, both are congruent.

4. Opposite of velocity

Based on point (3) above, it can be said that $v_{1}$ is opposite of $v_{2}$, that is $v_{1}=\neg v_{2}$ moreover, it can be written $v_{2}=\neg v_{1}$. Therefore that the general form applies that $\neg \neg v=v$ and $v \oplus \neg v \cong \emptyset$.

If $v_{i}^{t}=\left(\left(a_{k}, b_{k}\right)\right), k \uparrow_{1}^{\left\|v_{i}^{t}\right\|}$, then $\neg v_{i}^{t}=\left(\left(a_{k}, b_{k}\right)\right), k \downarrow_{1}^{\left\|v_{i}^{t}\right\|}=\left(\left(a_{\left\|v_{i}^{t}\right\|-k+1}, b_{\left\|v_{i}^{t}\right\|-k+1}\right)\right), k \uparrow_{1}^{\left\|v_{i}^{t}\right\|}$

Example:

$v_{i}^{t}=((1,3),(3,2),(4,5)) \rightarrow v_{i}^{t}=\left(\left(a_{1}, b_{1}\right),\left(a_{2}, b_{2}\right),\left(a_{3}, b_{3}\right)\right),\left\|v_{i}^{t}\right\|=3$

$\neg v_{i}^{t}=((4,5),(3,2),(1,3))$

$\neg \neg v_{i}^{t}=((1,3),(3,2),(4,5))$

5. Move "position plus velocity."

Suppose the position update, $x_{i}^{t+1}=x_{i}^{t}+v_{i}^{t+1}$ is operated by processing from the first sequence of transposition $v$ to position $x$, then the following sequence, until the final sequence of $v$.

For example:

$x_{1}^{0}=\left[\begin{array}{lllll}2 & 5 & 1 & 3 & 4\end{array}\right] \rightarrow x_{i}^{t}=\left[\begin{array}{llll}x_{i 1}^{t} & x_{i 2}^{t} & . . & x_{i d}^{t}\end{array}\right]$

$v_{1}^{0}=((1,3),(3,2),(4,5)) \rightarrow v_{i}^{t}=\left(\left(a_{1}, b_{1}\right),\left(a_{2}, b_{2}\right),\left(a_{3}, b_{3}\right)\right),\left\|v_{i}^{t}\right\|=3$

$x_{i}^{t+1}=x_{i}^{t}+v_{i}^{t+1}$

$x_{1}^{1}=x_{1}^{0}+v_{1}^{1}$

$x_{1}^{1}=\left[\begin{array}{lllll}2 & 5 & 1 & 3 & 4\end{array}\right]+((1,3),(3,2),(4,5))$ 


$$
\begin{aligned}
& x_{1}^{1}=\left[\begin{array}{lllll}
1 & 5 & 2 & 3 & 4
\end{array}\right]+((3,2),(4,5)) \\
& x_{1}^{1}=\left[\begin{array}{lllll}
1 & 2 & 5 & 3 & 4
\end{array}\right]+((4,5)) \\
& x_{1}^{1}=\left[\begin{array}{lllll}
1 & 2 & 5 & 4 & 3
\end{array}\right]
\end{aligned}
$$

6. Subtraction "position minus position."

For example, there are two positions $x_{i}^{t}$ and $x_{i}^{t+1}$. Subtraction $x_{i}^{t+1}-x_{i}^{t}$ is defined as a velocity of $v_{i}^{t+1}$. Therefore that by applying the velocity $v_{i}^{t+1}$ into position $x_{i}^{t}$ produce $x_{i}^{t+1}$. The difference is defined as follows:

$x_{i}^{t+1}-x_{i}^{t}=v_{i}^{t+1} \leftrightarrow x_{i}^{t}+v_{i}^{t+1}=x_{i}^{t+1}$

if $x_{i}^{t+1}=x_{i}^{t}$, then $x_{i}^{t+1}-x_{i}^{t}=v_{i}^{t+1}=\emptyset$. For example:

$x_{1}^{1}=\left[\begin{array}{lllll}1 & 2 & 5 & 4 & 3\end{array}\right]$ and $x_{1}^{0}=\left[\begin{array}{lllll}2 & 5 & 1 & 3 & 4\end{array}\right]$

$v_{1}^{1}=x_{1}^{1}-x_{1}^{0}=((1,3),(3,2),(4,5))$

7. Addition "velocity plus velocity."

Suppose there are two speeds $v_{1}$ and $v_{2}$, to increase the speed of $v_{1}$ with $v_{2}\left(v_{1} \oplus v_{2}\right)$, the addition operation is carried out using the transposition sequence $v_{1}$ then proceed with the transposition sequence $v_{2}$. Besides that, it can be defined as follows:

$v=v_{1} \oplus v_{2}$

$v=\left(\left(a_{1}, b_{1}\right),\left(a_{2}, b_{2}\right), \ldots,\left(a_{\left\|v_{1}\right\|}, b_{\left\|v_{1}\right\|}\right)_{1}\right) \oplus\left(\left(a_{1}, b_{1}\right),\left(a_{2}, b_{2}\right), \ldots,\left(a_{\left\|v_{2}\right\|}, b_{\left\|v_{2}\right\|}\right)_{2}\right)$

Example:

$$
\begin{aligned}
& v_{1}=((1,3),(3,2),(4,5)) \quad v_{2}=((3,4),(4,1)) \\
& v=v_{1} \oplus v_{2}=((1,3),(3,2),(4,5)) \oplus((3,4),(4,1)) \\
& v=((1,3),(3,2),(4,5),(3,4),(4,1))
\end{aligned}
$$

8. Multiplication "coefficient times velocity."

Suppose that $c$ is a coefficient and $(c \in \mathrm{R})$, then the multiplication between velocity $v$ and $c$ can be carried out as follows according to the condition of the coefficient value.

a. If $c=0$, then

$$
\begin{aligned}
& v^{\prime}=c . v \\
& v^{\prime}\|=c .\| v \| \\
& v^{\prime}\|=0 .\| v \| \\
& v^{\prime} \|=0 \\
& v^{\prime}=\varnothing
\end{aligned}
$$

b. If $0<c \leq 1, v$ cut to length: $v^{\prime} \|=\lceil c$. $\|v\|\rceil$. For example:

$$
\begin{aligned}
& v=((1,3),(3,2),(4,5)) \\
& \|v\|=3 \\
& v^{\prime}=c . v \\
& v^{\prime} \|=\lceil 0.1 * 3\rceil=\lceil 0.3\rceil=1 \\
& v^{\prime}=((1,3))
\end{aligned}
$$

c. If $c>1$, then $c$ is formed from $c=k+c^{\prime}$ which is $k=\lfloor c\rfloor, k \in(N>0), c^{\prime}=c-k$ dan $0<c^{\prime}<1$. So this case is defined as:

$v^{\prime}=\left(\sum_{1}^{k} v\right) \oplus\left(c^{\prime} * v\right)=v \oplus \mathrm{v} \oplus \ldots \oplus \mathrm{v} \oplus\left(c^{\prime} * v\right)$

$\left(c^{\prime} \cdot v\right)$ is calculated using conditions (b).

Example:

$$
\begin{aligned}
& v=((1,3),(3,2),(4,5)) \\
& \|v\|=3 \\
& c=2,5 \\
& k=\lfloor c\rfloor=\lfloor 2,5\rfloor=2 \text { and } c^{\prime}=c-k=2,5-2=0,5 \\
& \left\|v^{\prime}\right\|=\|v\|+\|v\|+\left(\left\lceil c^{\prime} *\|v\|\right\rceil\right)=3+3+[0,5 * 3\rceil=3+3+\lceil 1,5\rceil
\end{aligned}
$$


$\left\|v^{\prime}\right\|=3+3+2=8$

$v^{\prime}=((1,3),(3,2),(4,5)(1,3),(3,2),(4,5)(1,3),(3,2))$

d. If $c<1$, then the velocity is reversed $(v=\neg v)$ using the concept on slide 8 and the value $c$ be positive $c=|c|$. Therefore that the latest velocity can be operated using the following function.

$v^{\prime}=c . \neg v$, Where the value of $c$ be operated as in conditions (a), (b), and (c) in the previous slide. For example:

$v^{\prime}=c . \neg v$

$v^{\prime} \|=\left\lceil c^{\prime} *\|\neg v\|\right\rceil=\lceil 0,1 * 3\rceil=\lceil 0,3\rceil=1$

$v^{\prime}=((4,5))$

9. Distance between two position

The distance between the two particles is obtained by calculating the difference in the fitness value of the two positions.

10. The position update formula that has been modified is defined as follows:

$$
\begin{aligned}
& v_{i}^{t+1}=c_{1} \cdot v_{i}^{t} \oplus c_{2}\left(\left(p B e s t_{i}^{t}+\frac{1}{2}\left(g B e s t_{g}^{t}-p \text { Best } t_{i}^{t}\right)\right)-x_{i}^{t}\right) \\
& x_{i}^{t+1}=x_{i}^{t}+v_{i}^{t+1}
\end{aligned}
$$

However, in its implementation, it was found that the PSO's particle speed was updated too quickly, and the minimum objective function value sought was often overlooked. Therefore, in this study, we changed the position update representation Clerc [25] using the speed update formula developed by Shi and Eberhart [29]. The change of representation is carried out, hoping that particles are better at approaching the optimal solution and not rapidly converging (early convergence).

$v_{i j}^{t+1}=\theta \cdot v_{i j}^{t}+c_{1} r_{1}\left(\right.$ Pbest $\left._{i j}^{t}-x_{i j}^{t}\right)+c_{2} r_{2}\left(\right.$ Gbest $\left._{g j}^{t}-x_{i j}^{t}\right)$

$x_{i j}^{t+1}=x_{i j}^{t}+v_{i j}^{t+1}$

Equation (10) is the result of improvements that have been made by adding an inertia term $(\theta)$ to reduce the speed of the speed update formula. Usually, the value of $\theta$ is made so that the higher the iteration is passed, the smaller the particle speed be. This value varies linearly in the range of 0.9 to 0.4 .

The weight of this inertia is proposed by Shi and Eberhart [29] to reduce speed during iterations, which allows the birds to converge the target points more accurately and efficiently. High inertia weight values add to the portion of the global exploration process, while low values emphasize local search. To not focus too much on one part and keep looking for a new search area in a particular dimension space, it is necessary to look for the inertial weight $\theta$ which equals keeping global and local searches. To achieve that and speed up convergence, an inertial weight that decreases in value by increasing iterations is used with the formula:

$\theta_{t}=\theta_{\max }-\left(\frac{\theta_{\max }-\theta_{\min }}{i_{\max }}\right) i$

where $\theta_{\max }$ and $\theta_{\min }$ are the initial and final inertia values, $i_{\max }$ is the maximum number of iterations used, and $i$ is the current iteration.

11. The stopping criteria are the number of maximum iteration.

The pseudocode of the DPSO algorithm for the flow shop scheduling problem is presented in Fig. 1. 


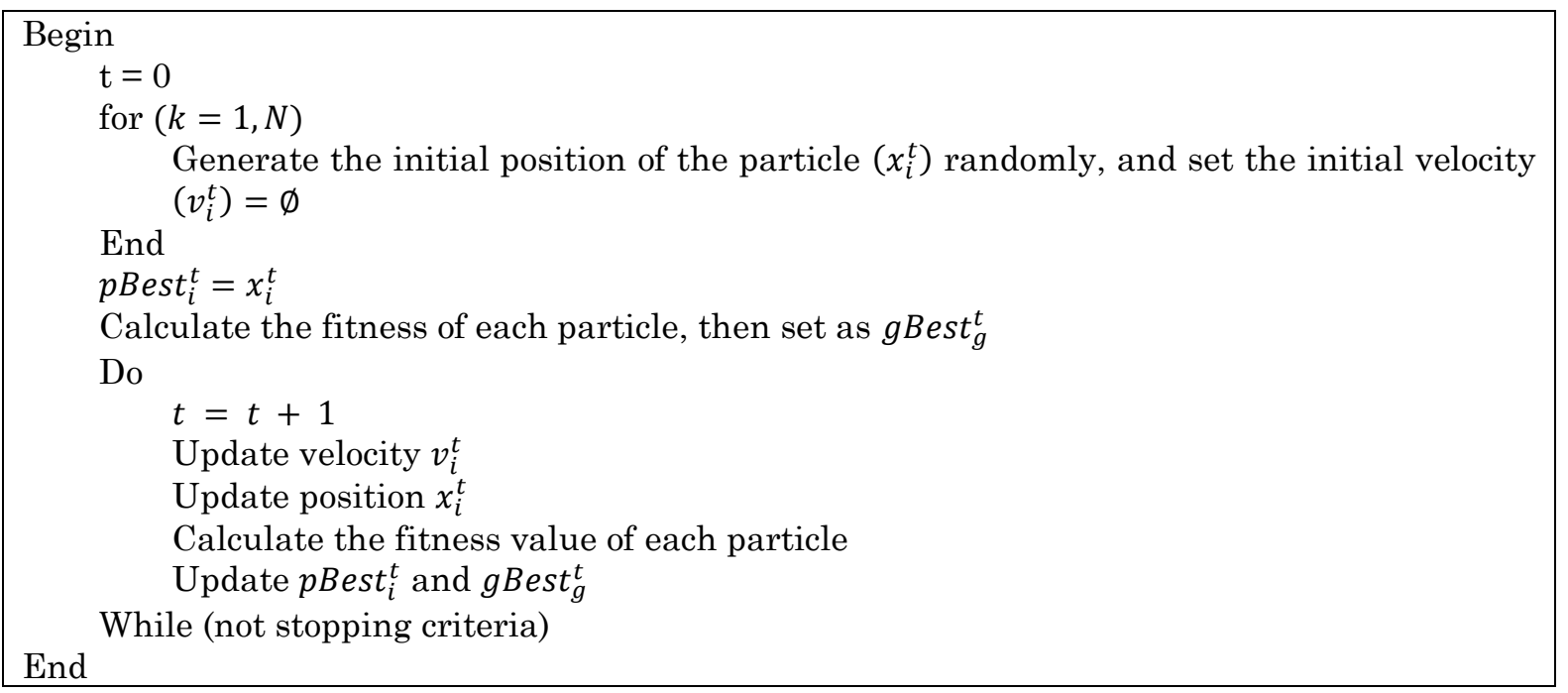

Fig. 1. The proposed HDPSO algorithm structure

\subsubsection{Modified Particle Swarm Optimization (MPSO)}

The second proposed algorithm is a combination of the PSO algorithm with the probability transition matrix. This algorithm is called Modified Particle Swarm Optimization (MPSO) [26]. In this study, we modified the MPSO algorithm to solve the PFSP. The proposed algorithm be explained as follows.

1. Particles position

$$
x_{i}^{t}=\left[\begin{array}{llll}
x_{i 1}^{t} & x_{i 2}^{t} & . . & x_{i d}^{t}
\end{array}\right]
$$

Where, $x_{i}^{t}$ is the position of the $i^{t h}$-particle in the $t^{t h}$-iteration, and the particle has as many as $d$ dimensions. It is expressed in a probability transition matrix that is randomly generated with intervals of 0 to 1 .

Example:

$x_{i}^{t}=\left[\begin{array}{lllll}0.1067 & 0.8687 & 0.4314 & 0.1361 & 0.8530\end{array}\right]$

2. Solution sequence

The solution sequence is generated based on the probability value of the transition matrix. Normalize first the probability transition matrix such that the probability value is more than equal to 0 and less than 1.

Example:

If $x_{i}^{t}=\left[\begin{array}{lllll}0.7749 & 1.2599 & 0.2638 & 0.5499 & -0.5132\end{array}\right]$, it be normalized to

$x_{i}^{t}=\left[\begin{array}{lllll}0.7749 & 1 & 0.2638 & 0.5499 & 0\end{array}\right]$ moreover, be transposed to be a new solution.

3. Transposition

Transposition is a way to exchange values on a particular dimension based on the index sequence of the position of the particles (by ascending or descending order).

Example:

a. Transposition by ascending order

$$
x_{i}^{t}=\left[\begin{array}{lllll}
0.1067 & 0.8687 & 0.4314 & 0.1361 & 0.8530
\end{array}\right] \rightarrow s_{i}^{t}=\left[\begin{array}{lllll}
1 & 5 & 3 & 2 & 4
\end{array}\right]
$$

b. Transposition by descending order

$$
x_{i}^{t}=\left[\begin{array}{lllll}
0.7749 & 1 & 0.2638 & 0.5499 & 0
\end{array}\right] \rightarrow s_{i}^{t}=\left[\begin{array}{lllll}
2 & 1 & 4 & 3 & 5
\end{array}\right]
$$

4. Distance between two position

The distance between the two particles is obtained by calculating the difference in the fitness value of the two positions. 
5. The position update formula used in this algorithm refers to equations (12) and (13).

6. The stopping criteria are the number of maximum iteration (itmax).

The pseudocode of the MPSO algorithm for the flow shop scheduling problem is presented in Fig. 2.

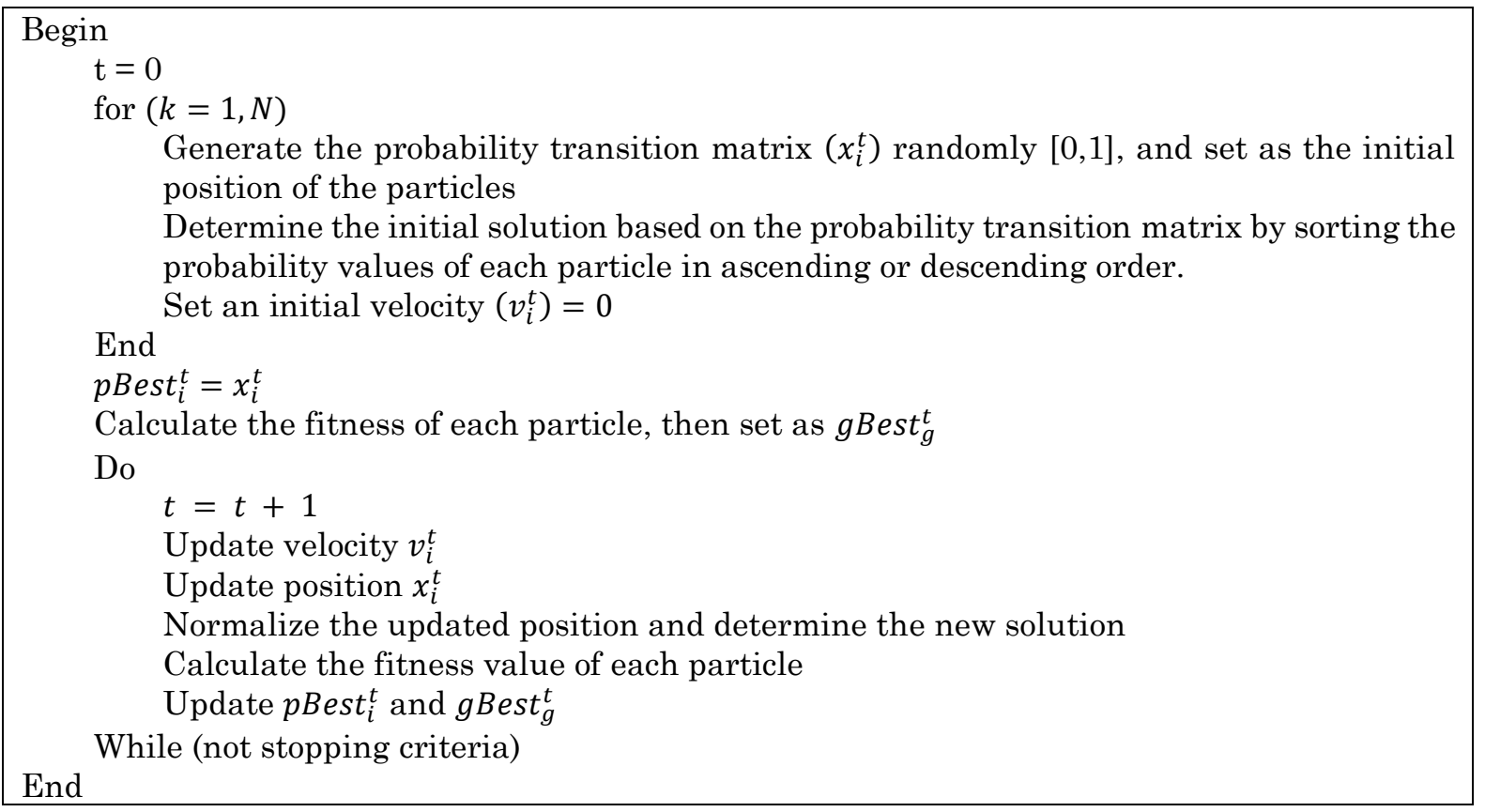

Fig. 2. The proposed MPSO algorithm structure

\subsection{The Case Study}

In this study, a case study was appointed by a cigarette company. The company produces a product if it receives orders from the customer. The company used a first-comefirst-served (FCFS) scheduling policy. It causes frequent delays in fulfilling order due dates. There are two types of lateness [1], such as tardiness and earliness. Each job must be processed in seven stages (machines) in the same order. The Job index, processing time, and due date are shown in Table 1.

Table 1. The Job index, processing time, and due date

\begin{tabular}{|c|c|c|c|c|c|c|c|c|}
\hline \multirow{2}{*}{$\begin{array}{l}\text { Job } \\
\text { Index }\end{array}$} & \multirow{2}{*}{$\begin{array}{l}\text { Due } \\
\text { Date } \\
\text { (day) }\end{array}$} & \multicolumn{7}{|c|}{ Processing Time (day) } \\
\hline & & M1 & M2 & M3 & M4 & M5 & M6 & M7 \\
\hline 1 & 31 & 7.62 & 10.99 & 25.97 & 4.76 & 12.99 & 0.67 & 5.00 \\
\hline 2 & 10 & 1.90 & 2.75 & 6.49 & 1.19 & 3.25 & 0.17 & 1.25 \\
\hline 3 & 15 & 3.81 & 5.49 & 12.99 & 2.38 & 6.49 & 0.33 & 2.50 \\
\hline 4 & 3 & 0.38 & 0.55 & 1.30 & 0.24 & 0.65 & 0.03 & 0.25 \\
\hline 5 & 10 & 1.90 & 2.75 & 6.49 & 1.19 & 3.25 & 0.17 & 1.25 \\
\hline 6 & 6 & 0.95 & 1.37 & 3.25 & 0.60 & 1.62 & 0.08 & 0.63 \\
\hline 7 & 10 & 1.90 & 2.75 & 6.49 & 1.19 & 3.25 & 0.17 & 1.25 \\
\hline 8 & 9 & 1.30 & 1.87 & 4.42 & 0.81 & 2.21 & 0.11 & 0.85 \\
\hline 9 & 9 & 1.30 & 1.87 & 4.43 & 0.81 & 2.21 & 0.11 & 0.85 \\
\hline 10 & 9 & 1.30 & 1.88 & 4.44 & 0.81 & 2.22 & 0.11 & 0.86 \\
\hline 11 & 6 & 0.95 & 1.37 & 3.25 & 0.60 & 1.62 & 0.08 & 0.63 \\
\hline 12 & 4 & 0.67 & 0.96 & 2.27 & 0.42 & 1.14 & 0.06 & 0.44 \\
\hline 13 & 1 & 0.19 & 0.27 & 0.65 & 0.12 & 0.32 & 0.02 & 0.13 \\
\hline
\end{tabular}




\subsection{Parameter Setting}

In experimental, We used some scenarios in the combination of tests. It consists of 9 combination parameters: population size $(\mathrm{N})$ and the maximum number of iterations (itmax). Population used 10, 50, 100, Iteration used 50, 250, 500. In addition, we set the other PSO parameters such as a) learning factor $\left(c_{1}=c_{2}=1\right)$; b) inertia term $\left(\theta_{\text {min }}=0,4\right.$ and $\left.\theta_{\max }=0,9\right)$ [30]. Each combination of parameters was tested for ten replications. The computational process was carried out with the help of Matlab R2017a software. It is carried out on computers Intel® Core ${ }^{\mathrm{TM}}$ i3-6006U CPU Processor @ 2.00GHz (4 CPUs). To evaluate the performance of HDPSO and MPSO algorithms, a paired t-test was carried out at the $95 \%$ significance level. [30]. On the other hand, the population and iteration affect the solution's quality and computational time. The test was conducted by the analysis of variance (ANOVA).

\section{Results And Discussion}

In this section, we compare the FCFS and the proposed algorithm. The computational test was carried out using nine combinations of PSO algorithm parameters. The evaluation results are presented in Table 2.

Table 2. computational result

\begin{tabular}{|c|c|c|c|c|c|c|c|c|c|c|c|}
\hline \multirow{2}{*}{$\mathrm{N}$} & \multirow{2}{*}{ Itmax } & \multirow{2}{*}{ FCFS } & \multirow{2}{*}{$\begin{array}{l}\text { Optimal } \\
\text { Solution }\end{array}$} & \multicolumn{4}{|c|}{ HDPSO } & \multicolumn{4}{|c|}{ MPSO } \\
\hline & & & & Avg & Std & Min & $\mathrm{t}$ & Avg & Std & Min & $\mathrm{t}$ \\
\hline \multirow{3}{*}{10} & 50 & 1000.29 & 291.05 & 315.42 & 12.81 & 297.81 & 27.82 & 328.25 & 25.75 & 298.93 & 23.55 \\
\hline & 250 & 1000.29 & 291.05 & 297.73 & 6.26 & 291.06 & 173.26 & 315.09 & 17.82 & 291.06 & 113.99 \\
\hline & 500 & 1000.29 & 291.05 & 293.17 & 1.91 & 291.05 & 270.99 & 299.45 & 6.38 & 291.09 & 236.43 \\
\hline \multirow{3}{*}{50} & 50 & 1000.29 & 291.05 & 295.78 & 3.73 & 291.06 & 177.27 & 311.01 & 15.81 & 291.05 & 222.22 \\
\hline & 250 & 1000.29 & 291.05 & 291.26 & 0.65 & 291.05 & 1074.93 & 293.97 & 2.94 & 291.05 & 678.26 \\
\hline & 500 & 1000.29 & 291.05 & 291.05 & 0.00 & 291.05 & 1795.06 & 292.72 & 2.99 & 291.05 & 1447.39 \\
\hline \multirow{3}{*}{100} & 50 & 1000.29 & 291.05 & 291.05 & 0.00 & 291.05 & 491.34 & 291.28 & 0.49 & 291.05 & 358.62 \\
\hline & 250 & 1000.29 & 291.05 & 291.05 & 0.00 & 291.05 & 1702.39 & 291.05 & 0.00 & 291.05 & 1614.39 \\
\hline & 500 & 1000.29 & 291.05 & 291.05 & 0.00 & 291.05 & 2956.09 & 291.05 & 0.00 & 291.05 & 2894.57 \\
\hline
\end{tabular}

Based on the computation test in Table 2, the proposed algorithms produce better solutions than the company's solution. The proposed algorithm gave an optimal solution in a short time. In addition, the HDPSO algorithm has a better performance than the MPSO algorithm. However, HDPSO has a slightly longer computation time. Based on the paired t-test result (Table 3), the null hypothesis was rejected. It shows the difference between the HDPSO and MPSO algorithms. HDPSO produced better results than MPSO. However, HDPSO was computationally longer than MPSO.

Table 4 shows the ANOVA results. The population size $(\mathrm{N})$ and maximum iteration (itmax) influence the quality of solutions HDPSO and MPSO algorithms. The alternative is that interaction does exist between the two factors. The ANOVA table shows a p-value of 0,003812 for HDPSO and 1,91E-09 for MPSO, which is smaller than $\alpha=0.05$. It indicates differences in the quality of solutions produced between the various population size categories and iteration. 
Table 3. paired $t$-test results for proposed algorithms

a) t-Test: Paired Two Sample for Means

b) t-Test: Paired Two Sample for Means

$\begin{array}{lrrlrr} & 315.417 & 328.247 & & 27.82032 & 23.54685 \\ \text { Mean } & 292.7693 & 298.2038 & \text { Mean } & 1080.165 & 945.7334 \\ \text { Variance } & 6.85226 & 92.68847 & \text { Variance } & 1008077 & 947334.4 \\ \text { Observations } & 8 & 8 & \text { Observations } & 8 & 8 \\ \text { Pearson Correlation } & 0.993048 & & \text { Pearson Correlation } & 0.988093 \\ \text { Hypothesized Mean } & & & \text { Hypothesized Mean } & \\ \text { Difference } & 0 & \text { Difference } & 0 \\ \text { Df } & 7 & \text { Df } & 7 \\ \text { t Stat } & -2.18502 & \text { t Stat } & 2.443385 \\ \text { P(T<=t) one-tail } & 0.032578 & & \text { P(T<=t) one-tail } & 0.022269 \\ \text { t Critical one-tail } & 1.894579 & & \text { t Critical one-tail } & 1.894579 \\ \text { P(T<=t) two-tail } & 0.065156 & \text { P(T<=t) two-tail } & 0.044537 \\ \text { t Critical two-tail } & 2.364624 & & \text { t Critical two-tail } & 2.364624\end{array}$

a) based on the average solution; b) based on the computational time

Table 4. Two-factor ANOVA result for proposed algorithms

a) ANOVA (HDPSO test)

\begin{tabular}{|c|c|c|c|c|c|c|}
\hline Source of Variation & SS & $\mathrm{df}$ & MS & $\mathrm{F}$ & $\mathrm{P}$-value & F crit \\
\hline Sample & 8267,508 & 2 & 4133,754 & 28,85902 & $3,45 \mathrm{E}-10$ & 3,109311 \\
\hline Columns & 3833,363 & 2 & 1916,682 & 13,38095 & $9,52 \mathrm{E}-06$ & 3,109311 \\
\hline Interaction & 2410,405 & 4 & 602,6011 & 4,206946 & 0,003812 & 2,484441 \\
\hline Within & 11602,41 & 81 & 143,2396 & & & \\
\hline Total & 26113,68 & 89 & & & & \\
\hline \multicolumn{7}{|l|}{ b) ANOVA (MPSO test) } \\
\hline Source of Variation & SS & $\mathrm{df}$ & MS & $\mathrm{F}$ & $\mathrm{P}$-value & $\mathrm{F}$ crit \\
\hline Sample & 2134,902 & 2 & 1067,451 & 43,41859 & $1,53 \mathrm{E}-13$ & 3,109311 \\
\hline Columns & 1381,738 & 2 & 690,8688 & 28,1011 & $5,38 \mathrm{E}-10$ & 3,109311 \\
\hline Interaction & 1522,312 & 4 & 380,5781 & 15,48002 & 1,91E-09 & 2,484441 \\
\hline Within & 1991,395 & 81 & 24,58512 & & & \\
\hline Total & 7030,347 & 89 & & & & \\
\hline
\end{tabular}

\section{Conclusion}

The computational results show that the proposed algorithms were successful in solving the PFSP. It produces an optimal solution in the total earliness and total tardiness criterion. HDPSO produced better results than MPSO. However, HDPSO was computationally longer than MPSO. As future work, the proposed algorithms can be applied to the larger classes of combinatorial optimization problems in the literature. They can be compared with other intelligent swarm algorithms.

\section{References}

[1] Y.-D. Kim, "Minimizing total tardiness in permutation flowshops," European Journal of Operational Research, vol. 85, pp. 541-555, 1995. https://doi.org/10.1016/0377-2217(94)00029-C.

[2] M. Avriel, M. Penn, and N. J. D. A. M. Shpirer, "Container ship stowage problem: complexity and connection to the coloring of circle graphs," Discrete Applied Mathematics, vol. 103, pp. 271-279, 2000. https://doi.org/10.1016/S0166218X(99)00245-0. 
[3] V. A. Armentano and J. E. Claudio, "An application of a multi-objective tabu search algorithm to a bicriteria flowshop problem," Journal of Heuristics, vol. 10, pp. 463481, 2004. https://doi.org/10.1023/B:HEUR.0000045320.79875.e3.

[4] J.-S. Chen, J. C.-H. Pan, and C.-K. Wu, "Hybrid tabu search for re-entrant permutation flow-shop scheduling problem," Expert Systems with Applications, vol. 34, pp. 1924-1930, 2008. https://doi.org/10.1016/j.eswa.2007.02.027.

[5] B. Ekşioğlu, S. D. Ekşioğlu, and P. C. Jain, "A tabu search algorithm for the flowshop scheduling problem with changing neighborhoods," Computers \& Industrial Engineering, vol. 54, pp. 1-11, 2008. https://doi.org/10.1016/j.cie.2007.04.004.

[6] F. S. Erenay, I. Sabuncuoglu, A. Toptal, and M. K. Tiwari, "New solution methods for single machine bicriteria scheduling problem: Minimization of average flowtime and number of tardy jobs," European Journal of Operational Research, vol. 201, pp. 89-98, 2010. https://doi.org/10.1016/j.ejor.2009.02.014.

[7] Y. Marinakis, and M. J. C. Marinaki, "A hybrid multi-swarm particle swarm optimization algorithm for the probabilistic traveling salesman problem," Computers \& Operations Research, vol. 37, pp. 432-442, 2010. https://doi.org/10.1016/j.cor.2009.03.004.

[8] C.-W. Chiou, W.-M. Chen, C.-M. Liu, and M.-C. Wu, "A genetic algorithm for scheduling dual flow shops," Expert Systems with Applications, vol. 39, pp. 13061314, 2012. https://doi.org/10.1016/j.eswa.2011.08.008.

[9] W.-H. Wu, W.-H. Wu, J.-C. Chen, W.-C. Lin, J. Wu, and C.-C. Wu, "A heuristicbased genetic algorithm for the two-machine flowshop scheduling with learning consideration," Journal of Manufacturing Systems, vol. 35, pp. 223-233, 2015. https://doi.org/10.1016/j.jmsy.2015.02.002.

[10] N. Karimi, and H. J. C. Davoudpour, "A high performing metaheuristic for multiobjective flowshop scheduling problem," Computers \& operations research, vol. 52, pp. 149-156, 2014. https://doi.org/10.1016/j.cor.2014.01.006.

[11] H. F. Rahman, R. Sarker, and D. Essam, "A genetic algorithm for permutation flowshop scheduling under practical make-to-order production system," Computers \& Industrial Engineering, vol. 31, pp. 87-103, 2017. https://doi.org/10.1017/S0890060416000196.

[12] S. A. Basir, M. M. Mazdeh, and M. J. C. Namakshenas, "Bi-level genetic algorithms for a two-stage assembly flow-shop scheduling problem with batch delivery system," Computers \& Industrial Engineering, vol. 126, pp. 217-231, 2018. https://doi.org/10.1016/j.cie.2018.09.035.

[13] C. Yu, Q. Semeraro, and A. J. C. Matta, "A genetic algorithm for the hybrid flow shop scheduling with unrelated machines and machine eligibility," Computers \& Operations Research, vol. 100, pp. 211-229, 2018. https://doi.org/10.1016/j.cor.2018.07.025.

[14] X. Liu, L. Wang, L. Kong, F. Li, and J. J. Li, "A Hybrid Genetic Algorithm for Minimizing Energy Consumption in Flow Shops Considering Ultra-low Idle State," $\begin{array}{lllll}\text { Procedia CIRP, } & \text { vol. } & \text { 80, } & \text { pp. } & 192-196,\end{array}$ https://doi.org/10.1016/j.procir.2018.12.013.

[15] T. Varadharajan and C. J. Rajendran, "A multi-objective simulated-annealing algorithm for scheduling in flowshops to minimize the makespan and total flowtime of jobs," European Journal of Operational Research, vol. 167, pp. 772-795, 2005. https://doi.org/10.1016/j.ejor.2004.07.020.

[16] M. Bank, S. F. Ghomi, F. Jolai, and J. Behnamian, "Application of particle swarm optimization and simulated annealing algorithms in flow shop scheduling problem 
under linear deterioration," Advances in Engineering Software, vol. 47, pp. 1-6, 2012. https://doi.org/10.1016/j.advengsoft.2011.12.001.

[17] P. Jarosław, S. Czesław, and Ż. Dominik, "Optimizing bicriteria flow shop scheduling problem by simulated annealing algorithm," Procedia Computer Science, vol. 18, pp. 936-945, 2013. https://doi.org/10.1016/j.procs.2013.05.259.

[18] C.-J. Liao, C.-T. Tseng, and P. Luarn, "A discrete version of particle swarm optimization for flowshop scheduling problems," Computers \& Operations Research, vol. 34, pp. 3099-3111, 2007. https://doi.org/10.1016/j.cor.2005.11.017.

[19] S. Ponnambalam, N. Jawahar, and S. Chandrasekaran, "Discrete particle swarm optimization algorithm for flowshop scheduling," in Particle Swarm Optimization, ed: IntechOpen, 2009. https://www.intechopen.com/download/pdf/6275.

[20] F. P. Goksal, I. Karaoglan, and F. Altiparmak, "A hybrid discrete particle swarm optimization for vehicle routing problem with simultaneous pickup and delivery," Computers \& Industrial Engineering, vol. 65, pp. 39-53, 2013. https://doi.org/10.1016/j.cie.2012.01.005.

[21] X. Zheng, S. Zhou, and H. Chen, "Ant colony optimisation algorithms for two-stage permutation flow shop with batch processing machines and nonidentical job sizes," International Journal of Production Research, vol. 57, pp. 3060-3079, 2019. https://doi.org/10.1080/00207543.2018.1529445.

[22] S. Sheikh, G. Komaki, and V. Kayvanfar, "Multi objective two-stage assembly flow shop with release time," Computers \& Industrial Engineering, vol. 124, pp. 276292, 2018. https://doi.org/10.1016/j.cie.2018.07.023.

[23] B. Jarraya and A. Bouri, "Metaheuristic optimization backgrounds: a literature review," International Journal of Contemporary Business Studies, vol. 3, pp. 31-44, 2012. https://ssrn.com/abstract=2114335.

[24] D. P. Ronconi and E. G. Birgin, "Mixed-integer programming models for flowshop scheduling problems minimizing the total earliness and tardiness," in Just-in-Time systems, ed: Springer, 2012, pp. 91-105. https://doi.org/10.1007/978-1-4614-11239_5.

[25] M. Clerc, "Discrete particle swarm optimization, illustrated by the traveling salesman problem," in New optimization techniques in engineering, ed: Springer, 2004, pp. 219-239. https://doi.org/10.1007/978-3-540-39930-8_8.

[26] B. Santosa and N. Siswanto, "Discrete particle swarm optimization to solve multiobjective limited-wait hybrid flow shop scheduling problem," in IOP Conference Series: Materials Science and Engineering, 2018, p. 012006. https://doi.org10.1088/1757-899x/337/1/012006.

[27] L. A. J. Zurich, "Operations Research in Production Planning, Scheduling and Inventory Control," Journal of the Operational Research Society, vol. 26, pp. 568569, 1975. https://doi.org/10.1057/jors.1975.120.

[28] J. Kennedy and R. Eberhart, "Particle swarm optimization (PSO)," in Proc. IEEE International Conference on Neural Networks, Perth, Australia, 1995, pp. 1942 1948.

[29] Y. Shi and R. C. Eberhart, "Parameter selection in particle swarm optimization," in International conference on evolutionary programming, 1998, pp. 591-600. https://doi.org/10.1007/BFb0040810.

[30] R. Gangadharan and C. Rajendran, "Heuristic algorithms for scheduling in the nowait flowshop," International Journal of Production Economics, vol. 32, pp. 285290, 1993. https://doi.org/10.1016/0925-5273(93)90042-J. 